\title{
Tensões entre o local e o global: ruralidades contemporâneas e docência em escolas rurais
}

\begin{abstract}
Elizeu Clementino de Souza*
Ana Sueli Teixeira de Pinho**

Mariana Martins de Meireles ${ }^{* *}$

\section{Resumo}

O artigo objetiva investigar possíveis tensões entre o local e o global no contexto das ruralidades contemporâneas, enfatizando os tempos, ritmos e espaços construídos a partir das vivências de professores e alunos na organização das rotinas de escolas rurais. $O$ texto apresenta considerações teóricas resultantes de duas pesquisas no âmbito do Programa de Pós-graduação em Educação e Contemporaneidade - PPGEduC/Uneb. O recorte e a análise empreendidos centram-se na educação desenvolvida em espaços rurais e nas tensões presentes nesse contexto, tendo em vista problematizar questões concernentes às novas ruralidades contemporâneas. Essa discussão tem como eixo articulador as questões de tempos e ritmos em escolas com classes multisseriadas da Ilha de Maré que se articula com dilemas e tensões em torno da experiência vivenciada por professoras de Geografia da cidade que exercem a docência em espaços rurais no semiárido baiano. As pesquisas têm apontado dificuldades enfrentadas pela escola rural em considerar as diferentes temporalidades existentes no espaço rural em seus processos educativos, bem como dificuldades de articulação, nesses contextos de aprendizagens, entre as dimensões localglobal pelas quais passam o espaço contemporâneo. Esse movimento cria tensões para o trabalho docente, uma vez que torna complexa a articulação entre os tempos instituídos, padronizados e rígidos, com os tempos pessoais dos alunos e professores, considerando aspectos como faixa etária, histórias de vida, deslocamentos e as experiências sócio-histórico-geográficas dos sujeitos envolvidos nos processos de ensinar e aprender em contextos rurais na contemporaneidade.
\end{abstract}

Palavras-chave: local, global, ruralidades contemporâneas, escola rural, docência.

\footnotetext{
* Professor Doutor Titular da Universidade do estado da Bahia (Uneb), pesquisador CNPQ, coordenador do Projeto de Pesquisa Ruralidades diversas-diversas ruralidades (Fapesb; CNPq).

** Doutoranda e mestre em Educação e Contemporaneidade (PPGEduC/Uneb). Professora Assistente da Universidade Católica do Salvador (UCSal). Membro da equipe de pesquisa do Projeto de Pesquisa Ruralidades diversas-diversas ruralidades (Fapesb; CNPq). Bolsista Capes.

*** Mestranda em Educação e Contemporaneidade (PPGEduC/Uneb). Membro da equipe de pesquisa do Projeto de Pesquisa Ruralidades diversas-diversas ruralidades (Fapesb; CNPq). Bolsista CAPES. Salvador, Bahia, Brasil.
} 


\section{Elizeu Clementino de Souza - Ana Sueli T. de Pinho - Mariana M. de Meireles \\ Tensions between the local and the global: contemporary rural and teaching in rural schools}

\section{Abstract}

The paper aims to investigate potential tensions between local and global context of contemporary ruralities, emphasizing the times, rhythms and spaces constructed from the experiences of teachers and students in the organization of the routines of rural schools. The paper presents theoretical considerations resulting from two studies in the Graduate Program in Education and Contemporary - PPGEduC / UNEB. The clipping and analysis undertaken focus on education developed in rural areas and tensions present in this context in view, discuss issues concerning the new ruralities contemporary. This discussion has as its central theme the issues of timing and the rhythm in schools with multigrade classes Island Tide that articulates with dilemmas and tensions surrounding the experience lived by teachers of geography of the city engaged in teaching in rural areas in semi-arid region of Bahia. Research has pointed to difficulties faced by rural school to consider the different temporalities that exist in rural areas in their educational processes, as well as difficulties of articulation in these contexts of learning, between the local-global dimensions through which passes the contemporary space. This movement creates stress for teachers' work, since it complicates the relationship between the times established, standardized and rigid, with times of personal students and teachers, covering aspects such as age, life histories, movements and experiences socio-historical and geographical subjects involved in the processes of teaching and learning in rural settings in contemporary times.

Keywords: local, global, ruralities contemporary, rural school, teaching.

\section{Introdução}

Este artigo é parte integrante das reflexões realizadas no âmbito do Projeto de Pesquisa "Ruralidades diversas-diversas ruralidades: sujeitos, instituições e práticas pedagógicas nas escolas do campo Bahia/Brasil" desenvolvido em regime de colaboração entre a Universidade do Estado da Bahia/Uneb, a Universidade Federal do Recôncavo da Bahia/UFRB e a Universidade de Paris 13/Nord-Paris8/Vincennes - Saint Denis (França), através de parceria entre os seguintes grupos de pesquisa: Grafho - Grupo de Pesquisa (Auto)biografia, Formação e História Oral (PPGEduC/Uneb); CAF - Currículo, Avaliação e Formação (UFRB/Centro de Formação de Professores - Campus Amargosa); e o Centre de Recherche Interuniversitaire Experice (Paris 13/Nord-Paris 8/Vincennes - Saint Denis). Tais instuições com seus grupos de pesquisas articulam uma rede de investigação acerca das ações educativas que se desenvolvem em diferentes espaços rurais no Estado da Bahia-Brasil e na França, somando contribuições acumuladas ao longo de suas trajetórias. 
Especificamente com este texto intentamos investigar tensões entre o local e o global no contexto das ruralidades contemporâneas, enfatizando a docência nas escolas rurais e tomando a escola como lugar de aprendizagem e intervenção social capaz de promover o dinamismo local. É nesse cenário que se insere o presente texto, com o objetivo de identificar as tensões existentes nas escolas rurais, a partir do cruzamento de questões que emergem do exercício da docência de professoras de escolas com classes multisseriadas em torno da experiência do tempo vivenciado no contexto local das comunidades rurais, o tempo hegemônico proposto pela escola e o exercício da docência em escolas rurais de professoras de Geografia que habitam áreas urbanas. Para tanto, entrecruzamos pesquisas ${ }^{1}$ desenvolvidas no Programa de Pós-graduação em Educação e Contemporaneidade - PPGEduc/Uneb, tomando como eixo articulador a existência de distintas ruralidades que permeiam o território rural baiano, quais sejam: a atuação de professoras de escolas com classes multisseriadas da llha de Maré e as trajetórias de vida-profissão-formação de professoras de Geografia do semiárido baiano, ambas vinculadas ao projeto Ruralidades diversas-diversas ruralidades (SOUZA et. al. 2010).

A opção por entrecruzar tais pesquisas justifica-se pelo valor heurístico do rural contido em ambas, que entendem o rural como uma importante categoria para a compreensão dos dinamismos locais que implicam diretamente dinamismos globais. Nessa mesma direção, a escola rural com os seus sujeitos é compreendida como um lugar socioeducativo relevante na reconstrução do "local" rural, fazendo emergir nesse movimento a construção de uma nova ruralidade (AMIGUINHO, 2008a). Partindo então das especificidades de cada uma dessas pesquisas, pode-se avançar na compreensão de processos educacionais mais gerais.

Portanto, o presente texto sistematiza questões em torno do tempoespaço rural com suas distintas ruralidades ${ }^{2}$ e os itinerários de formação-profissão desses professores para problematizar a questão da Educação situada em espaços rurais na/no Bahia/Brasil, contemplando, dentre outras temáticas, os tempos e ritmos dos sujeitos, a formação de professores, as condições de trabalhos impostas, a infraestrutura das escolas, bem como as especificidades e as singularidades desses espaços, tendo em vista que estas questões implicam diretamente processos de ensinar e de aprender em territórios rurais.

A compreensão de rural, presente nesse texto, perpassa pelo entendimento de um rural como categoria que emerge de um contexto sócio-históricogeográfico-cultural, extrapolando a concepção de um rural ${ }^{3}$ eminentemente agrário, atrasado, inferior ao urbano, voltado especificamente a atividades de agricultura ou agropecuária, imprimindo uma noção de rural contemporâneo que está associada às questões da natureza e de seus processos produtivos, considerando-o como um "[...] lugar de vida, onde as pessoas podem morar, trabalhar, estudar com dignidade de quem tem o seu lugar, a sua identidade cultural" (FERNANDES, 2004, p. 137). Configura-se, nesse sentido, como um espaço de relações sociais, "espaço singular e ator coletivo" (WANDERLEY, 2000, p. 92), lugar do acontecer da vida. 
É a partir desse entendimento que consideramos que o espaço da llha de Maré constitui-se como um espaço rural contemporâneo, que não se funda, exclusivamente, em atividades agrícolas, em que "a ruralidade torna-se o rural da diversidade" (LIMA, 2005, p. 45), que se reveste de outras formas de produção da vida que acabam por influenciar na construção de relações tempo-espaciais bastante particulares. Neste lugar, llha de Maré, as identidades sociais são construídas a partir de marcadores tempo-espaciais que cruzam os saberes da cultura, próprias dos seus habitantes com o tempo da natureza, que tem a maré como seu principal marcador. De algum modo, também as trajetórias e o trabalho docente realizado pelas professoras da cidade que trabalham em escolas rurais se inserem nessa concepção de um rural contemporâneo mediatizados pela confluência de outros modos de vida presentes no exercício da profissão.

Essa compreensão de rural está presente nas Diretrizes Operacionais para a Educação Básica nas Escolas do Campo (2001), que compreende o espaço rural como espaço da floresta, da pecuária, das minas e da agricultura, mas os ultrapassa ao acolher em si os espaços pesqueiros, caiçaras, ribeirinhos e extrativistas. O campo/rural, nesse sentido, "mais do que um perímetro não-urbano, é um campo de possibilidades que dinamizam a ligação dos seres humanos com a própria produção das condições da existência social e com as realizações de sociedade humana" (BRASIL, 2001, p. 1). Encontram-se, ainda, nas Diretrizes, dois importantes fundamentos para a educação do campo: a superação da dicotomia entre rural e urbano e as relações de pertença diferenciadas e abertas para o mundo.

A partir dessas bases legais, busca-se uma educação pública, sobretudo rural, que valorize a identidade e a cultura dos povos rurais, numa perspectiva de formação humana e de desenvolvimento local sustentável, refletindo, assim, sobre a educação operacionalizada fora dos limites do espaço urbano. Essa atenção é pertinente e essa discussão é necessária, uma vez que o Brasil caracteriza-se por um grande número de municípios ${ }^{4}$ nos quais as relações sociais e econômicas centram-se nos valores, na vida e na cultura advindas dos espaços rurais, cabendo nesse contexto problematizarmos sobre a educação, a escola e a docência produzidas nesses espaços sociais.

Embora os problemas da educação não estejam localizados apenas no espaço rural, neste contexto a situação assume uma configuração ainda mais complexa e mais emblemática. A escolha pelas questões que envolvem a escola rural parte dessa premissa aliada com a representação preconceituosa que enfrenta a população dos espaços rurais que, cotidianamente, convive com a sustentada crença de que este é um lugar desprovido de arranjos econômicos mais elaborados e limitado, culturalmente, pelo seu modo de vida, historicamente inferiorizado em relação ao espaço urbano.

Essas representações são extremamente preconceituosas e transmitem uma visão também de que qualquer ensino serviria para a escola rural, ou 
seja, para um espaço inferior, um ensino inferior. Além disso, as dificuldades da vida enfrentadas pelos alunos das escolas rurais acabam, por vezes, lançandoos para fora deste espaço, conduzindo-os em direção às cidades, com uma esperança ilusória de mudança nos padrões de vida. Essas e outras questões são problematizadas neste artigo, no qual "a escola em meio rural aparece não como algo de obsoleto, mas sim como algo que pode ser portador de futuro". (CANÁRIO, 2008, p. 3).

Diante das narrativas em torno da escola rural socializada pelos sujeitos dessas pesquisas e das imagens sobre este espaço construídas historicamente, buscamos estabelecer um diálogo com Canário (2008), para justificar a definição das escolas rurais como objeto de estudo. Assim, vale considerar que: 1) o futuro das pequenas escolas situadas em contexto rural não constitui um problema interno ao sistema escolar, mas pelo contrário, corresponde a uma questão bem mais ampla, que diz respeito ao futuro do mundo rural, e, portanto, à configuração global da nossa sociedade; 2) o deslocamento da questão da escola em meio rural de um contexto técnico para um contexto político, que poderá contribuir para recolocar a questão da escola e da educação no terreno dos fins e não dos meios; 3 ) o enfrentamento do mundo rural como um terreno de resistência à "civilização do mercado", que poderá funcionar como um analisador dos mecanismos de alienação do trabalho escolar e das condições da sua eventual superação; 4) o equacionamento do contexto rural como um terreno potencialmente fecundo para a emergência de práticas educativas que ajudem a repensar criticamente a forma escolar.

Tecidas essas considerações, este texto não tem a pretensão de esgotar a temática, mas trazer para o centro dos debates as tensões existentes em torno da oferta educacional no meio rural, de modo que a escola rural possa educar as crianças e jovens, partindo das suas experiências locais a fim de alcançar uma compreensão do mundo que ultrapasse os limites do contexto rural vivido, em um movimento que articula questões do local e do global tensionadas, sobretudo na contemporaneidade.

\section{Escolas rurais, docência e suas tensões}

Historicamente, a escola rural vem sendo tratada como sinônimo do desvio daquilo que se projetou como ideal de escola, cuja herança está fundamentada numa visão urbanocêntrica que desvaloriza e desqualifica o espaço e o tempo rural, transformando-a, dessa forma, numa "não-escola". Ou seja, as experiências desenvolvidas no local em torno dos tempos e ritmos, bem como as especificidades da docência em territórios rurais, não têm sido alvo das reflexões dos educadores, especialistas e técnicos dos sistemas educacionais, no sentido de contribuir para delinear um projeto de escola rural que faça sentido para os sujeitos que habitam esses territórios de identidade, bem como para os professores que atuam em escolas rurais. 
Considerando a complexidade desse contexto, entendemos que "seria no interior das incontornáveis conceitualizações emergentes sobre o local que, provalmente, iríamos encontrar referências ao meio rural" (AMIGUINHO, 2008b, p.108). Nessa perspectiva, é possível considerar que é localmente que se dá a maior participação dos cidadãos e a conjugação de esforços de solidariedade, a fim de enfrentar as desigualdades sociais produzidas no contexto rural, além disso, é no espaço local que a escola existe na sua forma concreta, ainda que esta inserção, por vezes, seja ignorada pelos sistemas de ensino na elaboração dos currículos destinados às escolas rurais. Assim, "a problemática do 'local' rural surge, neste contexto, de alguma forma ofuscada, nas intervenções e nos trabalhos de investigação" (AMIGUINHO, 2008b, p.110), invisibilizando as questões da educação em espaços rurais, tratando-as de maneira inferior, superficial e por vezes marginal.

Inserida nesse contexto, a escola não tem assumido o lugar de uma instituição que estimula a promoção de meios e condições dignas de trabalho e autossustento dos sujeitos no território rural em que vivem. Ao contrário, as narrativas dos sujeitos de nossas pesquisas, quando perguntados sobre os conhecimentos ensinados pelas escolas às crianças e jovens rurais, revelam que "a escola tem ensinado aos meninos a sentirem vergonha daqui" ou ainda "a escola tem ensinado aos alunos a migrarem do rural para as áreas urbanas das cidades".

Desse modo,

tanto a falta quanto a presença desse tipo de escola na zona rural tem aparecido, com frequência, como um fator de migrações. Isso nos põe diante do fato de que as populações rurais demandam uma escola rural diversa da que conhecemos, menos para permanecer no campo do que para integrar-se de modo apropriado nas promessas da sociedade moderna e desenvolvida. (MARTINS, 2005, p. 1)

Assim, a emergência dos problemas e das demandas referentes à escolarização das crianças e jovens, habitantes do meio rural, tem ampliado o debate em torno da educação rural no Brasil e no mundo, especialmente na América Latina e em alguns países da Europa e aos poucos vem fazendo com que os pesquisadores da educação rural considerem que esta modalidade de educação está inserida no contexto de uma nova ruralidade. ${ }^{5}$ Isso significa a busca da superação da "(bem) sucedida fórmula da modernidade que Giddens (1992) designou por descontextualização, caracterizada pelo esvaziamento do espaço e do tempo em relação aos 'lugares' e da separação de um em relação ao outro" (AMIGUINHO, 2008b, p.112). E ao mesmo tempo em que significa o reconhecimento da necessidade de localizar e territorializar o rural, de modo que as experiências vivenciadas em torno dos tempos e ritmos na vida cotidiana possam ser incorporadas e valorizadas pela escola e tratadas como uma forma 
particular de cada sujeito se relacionar consigo mesmo, com o outro e com a natureza.

Segundo Canário (2008), as formas de socialização da escola, transformadas em formas hegemônicas de socialização, produziu formas de desvalorização dos modos de socialização anteriores à escola. Isso nos ajuda a compreender por que a escola, na sua origem, já nasce em ruptura com as comunidades locais. Esta ruptura justifica as dificuldades de inserção social da atividade escolar, uma vez que a atividade pedagógica se situa, tendencialmente,

fora do espaço social e fora da flecha do tempo (o espaço e o tempo escolares são distintos dos espaços sociais e do tempo histórico) o que implica uma relação de ruptura e não de continuidade com a experiência anterior dos aprendentes. Este facto está no cerne do défice de sentido do trabalho escolar, particularmente agravado com o processo de construção da escola de massas. (CANÁRIO, 2008, p. 39)

Esse processo de artificialização da vida, fabricado a partir das formas de socialização escolar, fez com que os sujeitos fossem apartados da própria vida e de suas próprias histórias, uma vez que suas experiências sociais não integravam os "cardápios" que constituíam os currículos das escolas rurais. Ou seja, alunos e professores, ao invés de sujeitos de direitos e protagonistas dos currículos escolares, passaram a ser meros destinatários. Além disso, exercer a docência nas escolas rurais tornou-se uma atividade muito complexa, pois.

particularmente em meio rural, foram considerados, na tradição da investigação educacional, como profundamente negativos no exercício profissional dos professores - isolamento profissional, físico, geográfico e pedagógico -, sem impacto da escola no meio local e viceversa. (AMIGUINHO, 2008b, p. 113)

Assim, este texto propõe, em certa medida, uma inversão paradigmática e epistemológica sobre as tensões que permeiam o contexto rural, os tempos e ritmos dos alunos e professores, a escola e a docência nesses espaços como centralidade da discussão, o que significa dar visibilidade ao local, uma vez que

nas movimentações e ações em torno da escola, que prenunciaram aquilo que se convencionou designar por dimensão local das questões educativas, é possível reconhecer manifestações persistentes da longa história da reação dos meios rurais à afirmação e imposição da escola como instituição moderna, própria da industrialização e da urbanização nascentes [...]. A missão de "integração" da escola nas sociedades rurais desenvol- 
veu-se sempre ao arrepio da cultura e da sociedade local rural, senão mesmo na lógica da submissão a um modelo existente dos particularismos próprios das diferentes localidades. (AMIGUINHO, 2008b, p. 114)

De fato, a modernidade foi concebida a partir de um projeto hegemônico, globalizante, rígido e homogêneo do mundo, e as escolas rurais estão inseridas nessa concepção. No entanto, a sociedade contemporânea nos convoca para o reconhecimento de que estamos em

\begin{abstract}
tempos de hibridização do mundo - a tecnologização da vida e a economização da natureza -, da mestiçagem de culturas, de diálogos de saberes, de dispersão de subjetividades, em que se está desconstruindo e reconstruindo o mundo, em que se estão ressignificando identidades e sentidos existenciais a contracorrente do projeto unitário e homogeneizante da modernidade. (LEFF, 2001, p. 9-10)
\end{abstract}

É precisamente nesse contexto que são tensionadas as ruralidades contemporâneas, que se fundam no pensamento sobre as relações entre o local e o global da pós-modernidade em confluência com os processos de globalização, "alertando para o risco de visualizar apenas um processo linear e hegemônico de globalização, sugerindo o desaparecimento do local, do nacional e do rural" (MOREIRA, 2005, p. 39). Rompendo com esta concepção, emerge um novo rural, "entendido como construção social e cultural, a noção de 'rural' é abordada como um artifício metodológico para revelar o caráter heterogêneo, móbil e dinâmico dos processos sociais" (CARNEIRO, 2005, p. 10).

Nesse cenário permeiam as tensões entre o local e global, onde o "lugar é, portanto, uma configuração instantânea de posições [...] e o espaço é um cruzamento de móveis [...] animado pelo conjunto dos movimentos que aí se desdobram. Espaço é um lugar praticado" (CERTEAU, 1998, p. 201-202). O rural configura-se, portanto, nesse lugar praticado, vivido e experienciado pelos seus sujeitos sociais, e é entendido "como lugar de produção de coisas ou relações sociais" (LIMA, 2005, p. 48). Entretanto, mesmo que o rural esteja inserido nessa dimensão do lugar, isso não quer dizer que suas relações sociais não se estabeleçam também por meio de um movimento global. Afinal de contas, "todos os lugares são mundiais" (SANTOS, 1996, p. 69), o lugar é então o mundo onde a vida acontece, onde as relações, os projetos e as coisas se materializam.

\title{
Desse modo,
}

não existe um espaço global, mas apenas espaços da globalização. [...] O Mundo, porém, é apenas um conjunto de possibilidades, cuja efetivação depende das oportunidades oferecidas pelos lugares. [...] o "Mundo" ne- 
Tensões entre o local e o global: ruralidades contemporâneas e docência em escolas rurais

cessita da mediação dos lugares, segundo as virtualidades destes para usos específicos. Num dado momento, o "Mundo" escolhe alguns lugares e rejeita outros e, nesse movimento, modifica o conjunto dos lugares, o espaço como um todo. É o lugar que oferece ao movimento do mundo a possibilidade de sua realização mais eficaz. Para se tornar espaço, o Mundo depende das virtualidades do lugar. (SANTOS, 1996, p. 271)

A partir dessa compreensão, o espaço e as relações que aí se estabelecem vivem um momento singular, no qual as interações do tipo local-local vão sendo substituídas, gradativamente, pelas relações do tipo local-global, pelas possibilidades de realização que o lugar oferece. Pode-se dizer ainda que "simultaneamente com este movimento de 'globalização', assiste-se hoje, no interior de cada Estado, a um movimento de sentido contrário, de valorização do 'local', com fortes implicações na política e administração da educação" (BARROSO, 1999, p. 129). Nesse movimento, os lugares ganham um papel intermediário entre o mundo, e os seus sujeitos, entre o que é local e o que é global. É também nesse contexto, inserido nessa dimensão local-global, que o rural se constitui como um espaço rico de possibilidades e enfrentamentos, propondo uma complementaridade com o espaço urbano, em detrimento de uma lógica urbano-centrada das relações estabelecidas entre urbano e rural como historicamente se perpetuou.

Essa perspectiva analítica que supera a ideia de um rural eminentemente agrário e inferior ao urbano nos permite visualizar a complexidade desse contexto que não se limita apenas na dimensão socioespacial, mas que chega com veemência nas escolas situadas em espaços rurais, onde tais questões implicam diretamente o exercício docente das professoras que atuam nesse espaço específico, mas nem sempre são contempladas nas dicussões e nas práticas desenvolvidas nas escolas rurais, sendo mais uma vez invisibilizadas nesse contexto.

Dessa forma, e para uma melhor compreensão da educação, da escola e da docência em espaços rurais, consideramos o lugar como uma importante categoria de análise espacial. É por meio da compreensão e do conhecimento do lugar que os professores das escolas rurais poderão compor suas práticas educativas de forma a respeitar e apreender sobre os saberes sociais dos alunos e alunas construídos mediante suas interações com o lugar onde produzem a vida. Assim, o lugar é entendido como o espaço vivido, local onde as relações do cotidiano acontecem constantemente, sofrendo suas mudanças. É um produto da experiência humana, lugar significa mais que o sentido geográfico de localização. O "lugar é o centro de significados construídos pelas experiências" (TUAN, 1983, p. 43).

Nesse sentido, o lugar (espaço rural) é tomado como espaço de aprendizagem, como "espaço aprendente", participa da ação coletiva como expres- 
são de identidade cultural e de solidariedade coletiva. Isso passa pelas redes de saber que circulam e se ligam num território. Um lugar, através da rede de ações (local-global) que ele favorece, através da atualização das redes de atores que 0 atravessam, é "aprendente" porque permite produzir marcas do conjunto de relações que nele se estabelecem e, sobretudo, dos processos de passagem recíprocos entre saberes formalizados e saberes da experiência.

Em decorrência desse entendimento da compreensão do lugar nos processos de ensinar e aprender e das tensões presentes nesse contexto é que se insere a relevância dos estudos que contemplem a questão dos tempos e ritmos em classes multisseriadas da llha de Maré, bem como das questões sobre as trajetórias de professoras de Geografia que atuam em escolas rurais e habitam áreas urbanas, uma vez que "a rígida lógica temporal da docência não é fácil de articular com os tempos de família, da condução, das distâncias" (ARROYO, 2011, p. 187). De fato, estudar os tempos e ritmos em escolas rurais articulados às trajetórias de professoras de Geografia tornou possível a constatação da dificuldade da escola e dos professores em cruzar os tempos do viver, de trabalhar e os tempos de escola. Os sujeitos inseridos nesses espaços "correm contra o tempo, têm de escolher entre tempos tão vitais. A escola tem seus tempos rígidos, predefinidos, enquanto os tempos da sobrevivência, do trabalho são imprevisíveis". (ARROYO, 2011, p.187).

Com essa configuração, as escolas rurais encontram dificuldades em lidar com as diferentes temporalidades e os singulares modos de vida existentes no espaço rural, o que gera tensões para o trabalho docente, uma vez que torna complexa a articulação entre os tempos instituídos, padronizados e rígidos, com os tempos pessoais dos alunos e professores, desconsiderando, por vezes, aspectos como faixa etária, histórias de vida, deslocamentos e as experiências sócio-histórico-geográficas dos sujeitos envolvidos nos processos de ensinar e aprender em contextos rurais na contemporaneidade.

\section{(In)conclusão}

Esse texto junta-se aos poucos estudos realizados no âmbito da docência em escolas rurais, contemplando questões e tensões contemporâneas. Em notas conclusivas, evidenciamos com este escrito que o trabalho docente em escolas rurais, sobretudo nos espaços onde ocorrem as pesquisas, enfrenta muitos desafios de ordem organizacional, pedagógica e de infraestrutura, perante as articulações entre local-global e suas implicações no exercício da profissão docente em escolas rurais. Somam-se ainda a essas questões aspectos concretos vinculados às condições de trabalho, profissionalização e carreira docente para os professores que atuam em espaços rurais. Tais questões possibilitam pensar esse espaço, a partir das experiências dos sujeitos envolvidos nos processos educativos, concebendo o lugar e suas tensões (local-global) como um importante referencial para apreender outros modos de ensinar e aprender em territórios rurais. 
De fato, o território rural já é cenário de muitas conquistas, as quais são frutos, sobretudo, de reivindicações dos movimentos sociais, tendo no espaço rural uma presença marcante. Mas, no que concerne a docência materializada nesses espaços, faz-se necessário ainda investir na formação dos profissionais que atuam no meio rural, formando-os para que conheçam a comunidade, o contexto no qual vão atuar e os alunos com quem viverão tempos e tempos. É preciso maiores investimentos no espaço rural, valorizando práticas de intervenção social, a oferta de uma educação de qualidade e professores com formação acadêmica e conhecimentos condizentes com o contexto de atuação. O papel exercido pela escola no contexto rural destaca-se pela necessidade do desenvolvimento de práticas educativas e educacionais vinculadas ao cotidiano, á cultura e à alternância, que possam favorecer a fixação do rurícola, diminuindo o êxodo rural e a hipertrofia das cidades.

Essas e outras problematizações que giram em torna da educação em escolas rurais perpassam por questões didático-pedagógicas singulares, pela compreensão do contexto rural e de suas implicações nos processos educativos, bem como pelas transformações espaciais contemporâneas, fruto das dinâmicas do capitalismo e da modernização dos espaços, da imprecisão para definição entre o rural e o urbano, que tem se constituído como uma realidade nas novas ruralidades contemporâneas a llha de Maré é um exemplo disso. Com essa configuração, as tensões entre o local e global, as fronteiras entre o rural e o urbano, antes bastante delimitadas, tornam-se cada vez mais imprecisas, imperceptíveis e fluidas. Essa nova realidade vem redefinindo o espaço rural que deixa de ser sinônimo somente do agrícola/atrasado e passa a ser compreendido como um espaço multifuncional, onde novas demandas surgem, reconfigurando, assim, esse "novo" mundo rural. Tal realidade não pode mais deixar de ser considerada quando se aventa movimentos educacionais em escolas rurais. Não há mais como manter o silêncio e a cortina que separa as escolas rurais de suas particularidades, tornando-a, pelo seu currículo e as práticas educativas desenvolvidas, mais urbanas que rurais.

Os tempos são de rompimento de fronteiras em que os espaços são múltiplos e suas singularidades devem ser consideradas e valorizadas. Vivemos em tempos de articulação entre rural e urbano, entre local e global, entre escola e as vidas de seus sujeitos. Desconsiderar essas novas posições do mundo e das relações contemporâneas nos espaços educativos é desconsiderar o modo como o movimento da vida e das coisas estão acontecendo, é ficar à margem diante da confluência de um mundo que se move e se articula, que se fragmenta e se globaliza, que é local, mas é também global. 


\section{Referências}

ARROYO, M. G. Imagens quebradas: trajetórias e tempos de alunos e mestres. 6. ed. Petrópolis, Vozes, 2011.

AMIGUINHO, A. J. M. Escola em meio rural: uma escola portadora de futuro? Revista Educação, Santa Maria, vol. 33, n. 1, p. 11-32, jan./abr. 2008a.

. A escola, a modernidade e o mundo rural. In: A escola e o futuro do mundo rural. Lisboa: Fundação Calouste Gulbenkian Fundação para a Ciência e a Tecnologia, março de $2008 \mathrm{~b}$.

BARROSO, J. A escola entre o local e o global: perspectivas para o século XXI: O caso de Portugal. In: BARROSO, J. A escola entre o local e o global: perspectivas para o século XXI. Lisboa: Educa, 1999.

BRASIL. Parecer CNE/CEB 036/2001, de 04 de dezembro de 2001: Diretrizes Operacionais para a Educação Básica das Escolas do Campo. Brasília: MEC/CNE/CEB, 2001.

BRASIL. Ministério da Educação. Conselho Nacional de Educação. Diretrizes operacionais para a Educação Básica nas Escolas do Campo. Brasília, DF, 2001.

CANÁRIO, R. Escola rural: de objecto social a objecto de estudo. Revista Educação, Santa Maria, vol. 33, n. 1, p. 33-44, jan./abr. 2008.

CARNEIRO, M. J. Ruralidades: novas ruralidades em construção. Revista Estudos - Sociedade e Agricultura, Rio de Janeiro, UFRRJ/DDAS/CPDA, n. 11, out. 1998.

Apresentação. In: MOREIRA, R. J. (Org.). Identidades sociais: ruralidades no Brasil contemporâneo. Rio de Janeiro: DP\&A, 2005.

CERTEAU, M. A invenção do cotidiano: as artes de fazer. Petrópolis: Vozes, 1998.

FERNANDES, B. M. Diretrizes de uma caminhada. In: ARROYO, M. G; CALDART, R. S.; MOLINA, M. C. Por uma educação do campo. Petrópolis: Vozes, 2004. p. 133-145.

LEFF, E. Saber ambiental: sustentabilidade, racionalidade, complexidade e poder. Petrópolis: Ed. Vozes, 2001.

LIMA, E. N. de. Novas identidades e novas ruralidades. Onde? In: MOREIRA, R. J. (Org.). Identidades sociais: ruralidades no Brasil contemporâneo. Rio de Janeiro: DP\&A, 2005.

MARTINS, J. de S. Educação rural e o desenraizamento do educador, Revista USP, n. 64, Coordenadoria de Comunicação Social, Universidade de São Paulo, dezembro 2004-fevereiro, 2005, p. 29-49. 
MOREIRA, R. J. (Org.). Ruralidades e globalizações: ensaiando uma interpretação. In: Identidades sociais: ruralidades no Brasil contemporâneo. Rio de Janeiro: DP\&A, 2005.

SANTOS, M. A natureza do espaço: espaço e tempo, razão e emoção. 3. ed. São Paulo: Hucitec, 1996.

SOUZA, E. C. de et al. Relatório Técnico de Pesquisa CNPq - Projeto Ruralidades diversas-diversas ruralidades: sujeitos, instituições e práticas pedagógicas nas escolas do campo, Bahia-Brasil. Salvador, 2010.

TUAN, Yi-Fu. Espaço e lugar: a perspectiva da experiência. Tradução. Lívia de Oliveira. São Paulo: DIFEL, 1983.

WANDERLEY. M. de N. B. A emergência de uma nova ruralidade nas sociedades avançadas - o "rural" como espaço singular e ator coletivo. Estudos - Sociedade e Agricultura, n. 15, p. 87-146, out. 2000.

\section{Notas}

${ }^{1}$ Fazemos referência a dois subprojetos vinculados à Pesquisa Ruralidades diversas - diversas ruralidades: sujeitos, instituições e práticas pedagógicas nas escolas do campo BahiaBrasil, realizada com financiamento do CNPq, Capes e Fapesb. O primeiro subprojeto vinculase à pesquisa de doutoramento de Ana Sueli Teixeira de Pinho e intitula-se "Tempos e ritmos em escolas com classes multisseriadas: um estudo das formas de organização do tempo escolar", o segundo subprojeto vincula-se à pesquisa de mestrado, desenvolvido por Mariana Martins de Meireles e intitula-se "Macabéas às avessas: trajetórias de professoras de Geografia da cidade na roça - narrativas sobre docência e escolas rurais".

2 Concebida neste texto "como expressão de identidades sociais abertas e múltiplas. Entendido dessa forma, o rural é um processo de construção social e cultural" (SOUZA et al. 2010, p. 47). Trata-se de "novas identidades em construção, postulando-as como expressão de novas relações campo-cidade" (CARNEIRO, 1998).

${ }^{3}$ Valorização do rural como lugar e como um modo de vida.

${ }^{4}$ Espaços dotados de pequenos núcleos urbanos.

${ }^{5} \mathrm{O}$ fim das "sociedades rurais" não significa o fim do rural: assiste-se, nas sociedades modernas, a um processo de "recomposição do rural" e da emergência de uma "nova ruralidade". Esta perspectiva contesta o desaparecimento das diferenças espaciais e sociais entre o rural e o urbano, e afirma a necessidade de uma nova abordagem que consiga "recompor o objeto e repensar a realidade rural em seus modos contemporâneos de recomposição ou reestruturação" (WANDERLEY, 2000).

\section{Correspondência}

Elizeu Clementino de Souza - Universidade do Estado da Bahia, Programa de Pós-graduação em Educação - Avenida Silveira Martins, 2555, CEP 41195.001, Cabula, Salvador, Bahia.

E-mail:esclementino@uol.com.br-anasuelipinho@yahoo.com.br-marianabahiana@hotmail.com

Recebido em 04 de novembro de 2011

Aprovado em 12 de março de 2012 